\title{
Ocean surgeonfish Acanthurus bahianus. I. The geography of demography
}

\author{
D. R. Robertson ${ }^{1, *}$, J. L. Ackerman ${ }^{2}$, J. H. Choat ${ }^{2}$, J. M. Posada ${ }^{3}$, J. Pitt ${ }^{4}$ \\ ${ }^{1}$ Smithsonian Tropical Research Institute (Panamá), STRI, Unit 0948, APO, AA 34002-0948, USA \\ ${ }^{2}$ School of Marine Biology and Aquaculture, James Cook University, Townsville 4811, Australia \\ ${ }^{3}$ Departamento de Biología de Organismos, Universidad Simón Bolívar, Apartado 89000, Caracas 1080-A, Venezuela \\ ${ }^{4}$ Benthic Ecology Laboratory, Bermuda Biological Station for Research, Biological, Station Lane, GE-01, Ferry Reach, Bermuda
}

\begin{abstract}
The ocean surgeonfish Acanthurus bahianus is a common inhabitant of reefs throughout the west and central Atlantic. We examined geographic variation in its demography among 10 locations spanning $56^{\circ}$ of latitude. These populations exhibit a great diversity of growth trajectories, as well as 3 -fold variation in terminal size and maximum longevity. There are strongly contrasting patterns of habitat variation in demography at 2 sites: at Bermuda, fish settle inshore, grow to about asymptotic size and then, when 2 to 6 yr old, relocate permanently to outer reefs, where they can reach 32 yr. At Belize, fish settle and attain $10 \mathrm{yr}$ on both inner and outer reefs, but grow faster and reach a $\sim 50 \%$ greater asymptotic weight on inner reefs. Habitat differences in growth at Belize largely span the range of variation among NW Atlantic locations. A. bahianus exhibits the fastest growth known for an acanthurid, and the strongest spatial variation in demography known for a tropical reef-fish. Maximum age, adult survivorship, terminal size and absolute growth rate are inversely related to temperature. However, relative growth rate is not: in all populations a similar percentage of mean asymptotic standard length $\left(L_{\infty}\right)$ is achieved at 1, 2 and $3 \mathrm{yr}$, and then growth effectively ceases. Variation in longevity is related to temperature, and is largely independent of size. Variation in growth and size is related strongly to both habitat and temperature effects, and the rate of growth appears to set terminal size. High longevity at 3 isolated oceanic islands seems to reflect a temperature effect, rather than an island effect.
\end{abstract}

KEY WORDS: Acanthuridae - Acanthurus bahianus - Tropical West Atlantic · Otolith · Longevity · Growth $\cdot$ Size $\cdot$ Temperature

\section{INTRODUCTION}

The ocean surgeonfish Acanthurus bahianus is abundant in shallow reef habitats throughout the tropical NW Atlantic as far north as Bermuda. It also occurs commonly along the northern and central coasts of Brazil, at all but the smallest of the Brazilian offshore islands, and at both oceanic islands (Ascension and St. Helena) in the south-central Atlantic (Randall 2002, Rocha et al. 2002). This species is both one of the most widely distributed tropical Atlantic reef-fishes and one of the commonest, small (up to $\sim 600 \mathrm{~g}$ ), benthicfeeding herbivorous fishes on coral and rocky reefs throughout its range (e.g. Lewis \& Wainwright 1985, Edwards 1990, Chapman \& Kramer 1999, Ferreira et al. 2004, authors' obs.).

Information on age and size structures of populations, as well as individual longevity and growth rates, and how these demographic parameters vary in relation to environmental conditions, provide the necessary context for assessing natural mechanisms that control abundance and population dynamics. Largescale comparisons such as we present here provide basic information on the realised range of demographic variation that is essential for interpreting the results of more detailed studies at particular localities. 
As yet there are no descriptions of the range of natural variation in the demography of any broadly distributed tropical reef-fish in the Atlantic, although at least 1 lutjanid in this area displays considerable latitudinal variation in size and longevity (Luckhurst et al. 2000).

Here we provide a basic description of range-wide variation in the longevity, growth and size of one of the most widely distributed Atlantic reef-fishes, and assess how its demographic characteristics vary across a large latitudinal gradient, between habitats at the same location, and in relation to the isolation of populations. Annual growth increments in the otoliths of tropical Atlantic fishes have provided reliable estimates of adult age in a variety of taxa (Bullock et al. 1992, Sadovy et al. 1992, Bush et al. 1996, Luckhurst et al. 2000, Manickchand-Heilman \& Phillip 2000, Choat et al. 2003). Our assessment of variation in the demography of Acanthurus bahianus relies on otolith-based, size-at-age data obtained from population samples at 10 study locations. These span the $56^{\circ}$ latitudinal range of persistent populations of this species in the NW, south and central Atlantic. They include highly isolated oceanic islands, offshore islands and continental shores, and were selected to include a wide range of states in latitude (sea temperature), habitat characteristics, and degree of site-isolation. We also compare the relative magnitudes of local habitat variation in demography (at 2 locations) and large scale variation among locations in the NW Atlantic. This paper expands on the partial presentation of data by Choat \& Robertson (2002). In a companion paper (Robertson et al. 2005, this volume), we discuss effects of fishing on the demography of A. bahianus.

\section{MATERIALS AND METHODS}

Study areas. We sampled Acanthurus bahianus at 10 localities between $33^{\circ} \mathrm{N}$ and $23^{\circ} \mathrm{S}$ where there are persistent populations of this species (Fig. 1). These comprised 5 locations spread over $23^{\circ}$ of latitude in the NW Atlantic, Barbados, Los Roques and Las Aves archipelagos (Venezuela), Punta de San Blas (Panama), Carrie Bow Cay (Belize), Lee Stocking Island (Bahamas) and Bermuda; and 3 spanning $15^{\circ}$ degrees of latitude in the south Atlantic, Cabo Frio (Brazil), and 2 mid-ocean islands (Ascension and St. Helena). Table 1 shows dates of sampling and mean sea surface temperatures (SST) at these sites (obtained from International Global Ocean Services System satellite data spanning 1982 to 2003: IGOSS nmc Reyn_Smith0Iv1 weekly SST available from http://ingrid.ldgo.columbia.edu).

Habitat characteristics of study areas. The characteristics of our study areas at Lee Stocking, Los Roques, Barbados and San Blas are described in Choat et al. (2003).

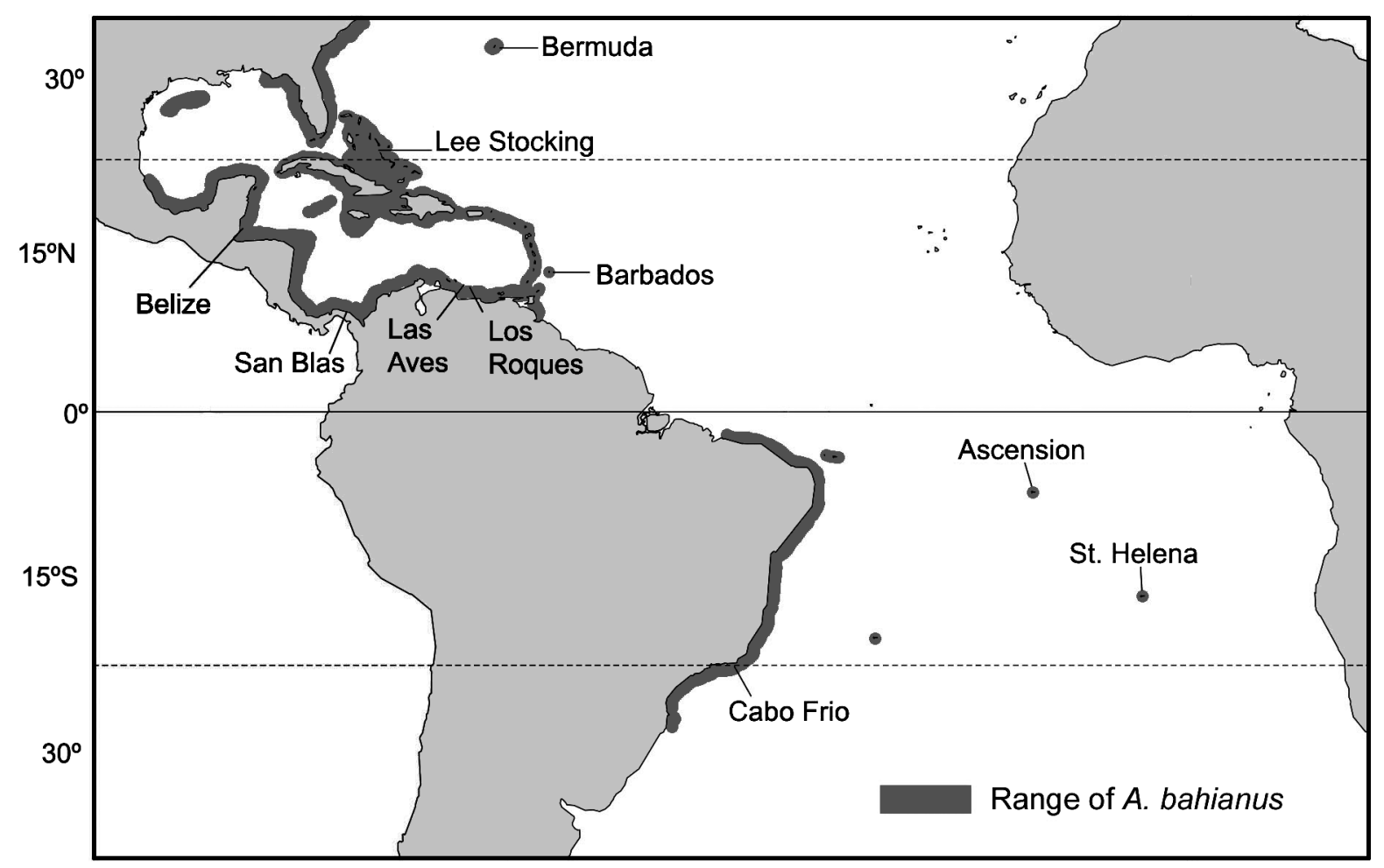

Fig. 1. Study sites at which demographic data on Acanthurus bahianus were obtained 
Table 1. Study sites arranged in order of (absolute) latitude, with their mean sea surface temperatures (MST) and sampling dates

\begin{tabular}{|lrcl|}
\hline Locality & Latitude & MST $\left({ }^{\circ} \mathrm{C}\right)$ & Sampling dates \\
\hline Ascension & $8.0^{\circ} \mathrm{S}$ & 26.0 & March-June 1997 \\
Panamá & $9.5^{\circ} \mathrm{N}$ & 28.0 & $1995-1997$ \\
Venezuela Los Roques & $11.8^{\circ} \mathrm{N}$ & 27.1 & July 2000, August 2002 \\
\multicolumn{1}{c}{ Las Aves } & $12.0^{\circ} \mathrm{N}$ & 27.1 & August 2002 \\
Barbados & $13.2^{\circ} \mathrm{N}$ & 27.6 & July 2000 \\
St. Helena & $15.9^{\circ} \mathrm{S}$ & 22.6 & June-July 1997 \\
Belize & $16.8^{\circ} \mathrm{N}$ & 28.1 & September 2002 \\
Brazil (Cabo Frio) & $22.9^{\circ} \mathrm{S}$ & 24.3 & October 1997 \\
Bahamas (Lee Stocking) & $23.8^{\circ} \mathrm{N}$ & 26.9 & November 1998 and 1999 \\
Bermuda & $32.3^{\circ} \mathrm{N}$ & 22.9 & October 2001, July 2002 \\
\hline
\end{tabular}

formation on the size and age structure of the population. To do so, on each dive we swam in haphazardly chosen directions and collected adults in the order in which they were encountered, regardless of size. However, we also were careful to collect the largest individuals we saw at each study location.

Acanthurus bahianus does not exhibit sexual size dimorphism and has a 1:1 sex ratio (Reeson 1983). There also are no obvious sexual differences in colour or shape in this species. Ocean surgeonfish are encountered either singly (they are territorial to some ex-

At Belize, fish were collected within $10 \mathrm{~km}$ of Carrie Bow Key, which is situated on the outer barrier reef of central Belize. We sampled 2 major habitats: (1) outer reefs - the outer slopes of the outer barrier reefs and channels between those reefs, and (2) inner reefspatch reefs in the lagoon 2 to $5 \mathrm{~km}$ inshore from the outer barrier (see Macintyre \& Aronson 1996 for description).

In Bermuda, we also sampled inner and outer reefs. Inner reefs included those in Castle Harbour lagoon (inside the island), along the northern shoreline of the island and in the shallow (2 to $10 \mathrm{~m}$ deep) lagoon on the northern side of the island. We sampled outer reefs with dense hard coral development at 7 to $25 \mathrm{~m}$ depths along the northern and southern rims of the Bermuda platform.

The 2 small volcanic islands Ascension and St. Helena Islands, in the central south Atlantic, have rocky shorelines with areas of sand and scattered boulders (Edwards 1990). Acanthurus bahianus was collected within $\sim 100 \mathrm{~m}$ of the shore at depths between 1 and $20 \mathrm{~m}$ at both islands.

Around Cabo Frio, the coastline consists of rocky islands and headlands interspersed with sandy beaches. Shallow parts $(<\sim 7 \mathrm{~m}$ depth) of rocky areas are dominated by dense stands of macroalgae (Ferreira et al. 2001). Sampling was done on various reefs within $25 \mathrm{~km}$ northward of the tip of Cabo Frio, at depths between 3 and $25 \mathrm{~m}$.

The offshore archipelago of Las Aves, $50 \mathrm{~km}$ west of Los Roques, has a range of habitats very similar to the latter (see Choat et al. 2003). We sampled Acanthurus bahianus in similar habitats in both those reef systems.

Field sampling. At each location we collected Acanthurus bahianus from at least 5 widely dispersed (separated by several kilometres) sites that covered a representative range of the habitats used by the ocean surgeonfish. Using polespears, we fished both juveniles (aiming to include the smallest available) and a representative sample of the adult size range, to provide in- tent) or in roaming feeding schools, and do not form territorial pairs or harems as do Indo-Pacific acanthurids that show sexual size dimorphism (Robertson 1985). We did not sample sexually active individuals; hence it is unlikely that inadvertent sexual biases in our sampling could have affected the patterns described here.

Age and growth analyses. All individuals were measured (standard length, SL, mm) and weighed (total wet weight) to the nearest $\mathrm{g}$. Sagittae were removed, cleaned and stored dry; 1 sagitta from each pair was weighed to the nearest $0.1 \mathrm{mg}$. Otoliths were prepared and increments counted following Choat \& Axe (1996), and Choat et al. (2003). Sectioned otoliths were examined under compound and dissecting microscopes using transmitted light. Two separate counts were made (by J. L. Ackerman) of increments along a consistent axis of each otolith, with a 3rd count in the case of any discrepancy. For any fish that initial inspection indicated was $<1$ yr old, counts were made of presumed daily rings in the otoliths.

To confirm that increments in the otoliths of large Acanthurus bahianus represented annuli, we netted, tagged and injected adults with tetracycline, then released them at their capture sites. This was done at Lee Stocking in 1999 and at San Blas in 1997. Return rates of tagged fish a little over 1 yr later were low: we saw (and recaptured) only 3 of 53 tagged fish at Lee Stocking, and found none of 10 tagged fish at San Blas.

For each locality an average growth curve was generated from size-at-age data obtained from the analyses of all sagittae from which consistent readings were obtained (1202 of 1279 individuals). Lifetime growth trajectories were estimated by fitting von Bertalanffy growth functions, VBGF $\left(L_{t}=L_{\infty}(1-\exp \right.$ $\left(-K^{\left(t-t_{0}\right)}\right)$, where $L_{t}$ is the estimated standard length at Age $t, L_{\infty}$ is the mean asymptotic standard length, $K$ is a curvature parameter, and $t_{0}$, is the age at which fish have a theoretical length of 0 . Because VBGF parameter estimates can be sensitive to the range of ages and sizes used (Ferreira \& Russ 1994, Craig 1999), inter- 
cepts were initially constrained to the average size of settlers collected at San Blas over a 4 yr period, i.e. 27 mm SL (see Robertson 1992). Subsequently, $t_{0}$ was constrained to 0 all locations, approximating the value attained by constraining length intercepts. This was done to reduce problems with variation in $K$ that arise from sampling bias in species that have 'square' growth curves like those of Acanthurus bahianus.

Similarities of growth patterns at different locations were assessed using 3 comparisons: (1) of 95\% confidence regions of $K$ and $L_{\infty}$ (Kimura 1980, Meekan et al. 2001, Choat et al. 2003); (2) of relative size-at-age (average $\%$ of $L_{\infty}$ at Years 1, 2 and 3); and (3) of instantaneous rates of growth at 0.5, 1 and 2 yr. Instantaneous growth rates were estimated using a bootstrapping method, following Ackerman (2004): For each location size-age data pairs were randomly chosen $\mathrm{n}$ times, where $\mathrm{n}$ represents the actual sample size for that location. For each randomly chosen data set, the von Bertalanffy growth model was calculated with $t_{0}=0$. Based on Porch et al.'s (2002) formula, the growth rate $\left(\mathrm{mm} \mathrm{yr}^{-1}\right)$ at time $t(0.5,1$ and $2 \mathrm{yr}$ ) was calculated as $\mathrm{d} L_{t} / \mathrm{d} t=K\left(L_{\infty}-L_{t}\right)$, where $L_{\infty}$ and $K$ are as described in the von Bertalanffy equation and $L_{t}$ is the expected size at Age $t$. This complete process was repeated 250 times for each population, yielding a mean instantaneous growth rate (with $95 \%$ confidence limits: see Manly 1997) at each age. We use bias-adjusted instantaneous growth rates, where the bias is calculated as the mean of the iterations subtracted from actual growth rates (based on the actual data and VBGF parameters for that data).

Mortality rates, and hence survivorship rates, at the different localities were calculated using log-linear regressions of age-frequency data. Following standard fisheries methods of catch-curve analysis, fish younger than the peak age mode were excluded from those analyses.

Assessing environmental influences on spatial variation in demography. Because of the locations of major cool and warm ocean currents, the annual temperature cycle, which controls the seasonality of fish growth (Conover 1990), is not closely linked to latitude among our sites. For example, the average temperature at Ascension $\left(8^{\circ} \mathrm{S}\right)$, is substantially less than that at both the Bahamas $\left(23.8^{\circ} \mathrm{N}\right)$ (Table 1$)$. Here we use mean sea surface temperature (MST) at each location as a proxy for the level of seasonal limitation on growth, and assess how variation in demographic characteristics of Acanthurus bahianus is related to it. To determine the extent of local, habitat-related variation in demography we compared demographic characteristics of subpopulations in broadly equivalent pairs of structurally different, well separated (by several kilometres) habitats at both Belize and Bermuda, i.e. inshore, sheltered (lagoonal) reefs and outer reefs (barrier reefs at Belize) that face the open ocean.

\section{RESULTS}

\section{Ageing from otoliths}

Regularly spaced, easily discernible and readily countable increments (Fig. 2A) were evident in $94 \%$ of adult otoliths from all 10 populations, although otoliths from Panamanian fish required additional polishing and careful adjustment of light conditions in order to obtain increment counts. Otoliths of 2 of the 3 tagged fish recaptured

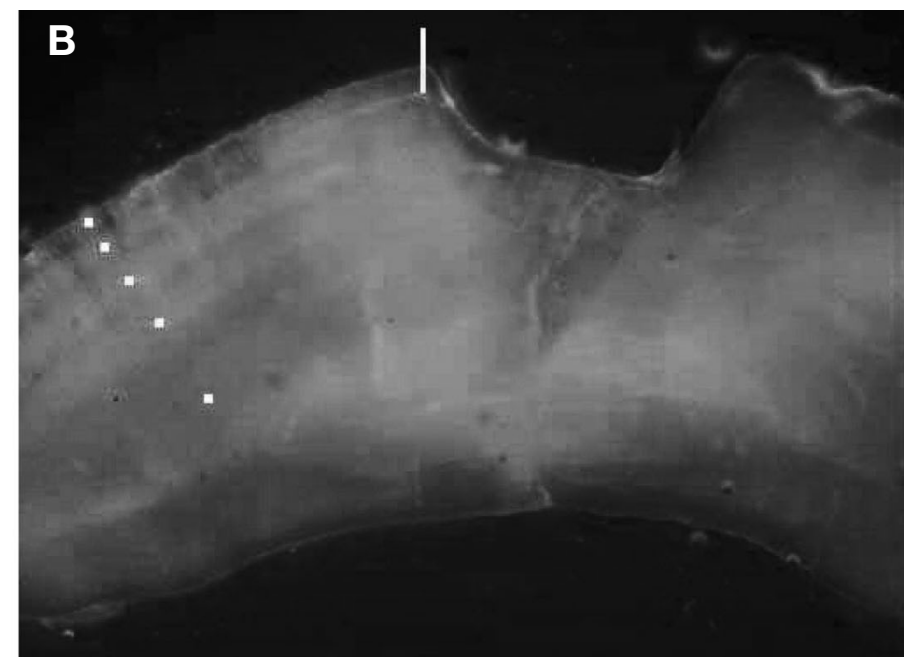

Fig. 2. Acanthurus bahianus. Sections of sagittal otoliths. (A) Sagittae from 4 localities, with 2st, 5 th, 10th, etc. increments indicated by white dots. i: San Blas, $134 \mathrm{~mm}$ standard length (SL) individual, 1 increment; ii: Barbados, $115 \mathrm{~mm}$ SL individual, 15 increments; iii: Santa Helena, $205 \mathrm{~mm}$ SL individual, 21 increments; iv: Bermuda, $185 \mathrm{~mm}$ SL individual, 27 increments. (B) Sagitta of a 5 yr old fish from Lee Stocking collected about 1 yr after being tagged and injected with tetracycline; increments indicated by white dots and tetracycline mark by white line 
at Lee Stocking $>1$ yr after they were initially tagged had a tetracycline mark visible under UV illumination (Fig. 2B). Using these marks we compared the actual versus predicted pattern of increment formation over that period: if increments are annuli, then the time from mark to recapture should equal [(the width from the tetracycline mark to the otolith edge/width of the last complete increment $) \times 1$ yr] (see Cappo et al. 2000). From this relationship the estimated times from mark to recapture in these 2 fish were 320 and $363 d$, or 82 and $95 \%$ of the actual times (390 and $383 \mathrm{~d}$ ), respectively. These data indicate that increments in otoliths of adult Acanthurus bahianus are indeed annuli.

In all 10 populations regressions of sagittal weight on age in each population yielded significant, and typically strong, power relationships, indicating that sagittae continue growing in old fish (Fig. 3): Belize: $y=373 x^{1.17}$, Panamá: $y=1503 x^{1.52}$, Barbados: $y=$ $2200 x^{1.54}$, Los Roques: $y=1889 x^{1.56}$, Las Aves: $y=$ $1115 x^{1.42}$, Bahamas: $y=3071 x^{1.75}$, Ascension: $y=$ $2880 x^{1.69}$, Cabo Frio: $y=4063 x^{1.90}$, Bermuda: $y=$
$4427 x^{1.72}$, St. Helena: $y=3654 x^{1.79}$. Thus, because the otoliths of Acanthurus bahianus grow throughout the life of the fish, and have regularly formed growth increments, they are suitable for ageing individuals (cf. Fowler \& Doherty 1992).

\section{Geographic variation in demography}

Lifetime growth trajectories. Lifetime growth curves in all populations of Acanthurus bahianus show that there is an initial period of very rapid growth, and that asymptotic length is reached early in life (Fig. 4). At each location there was considerable scatter in size-atage data, particularly at about the age when asymptotic length is achieved, leading to moderate $r^{2}$ values for VBGFs (Table 2). There was considerable diversity in growth trajectories among the different locations, including those within the Caribbean proper (Belize, Panamá, Venezuela and Barbados) and locations with similar $L_{\infty}$ values (Fig. 5). Variation in growth trajecto-
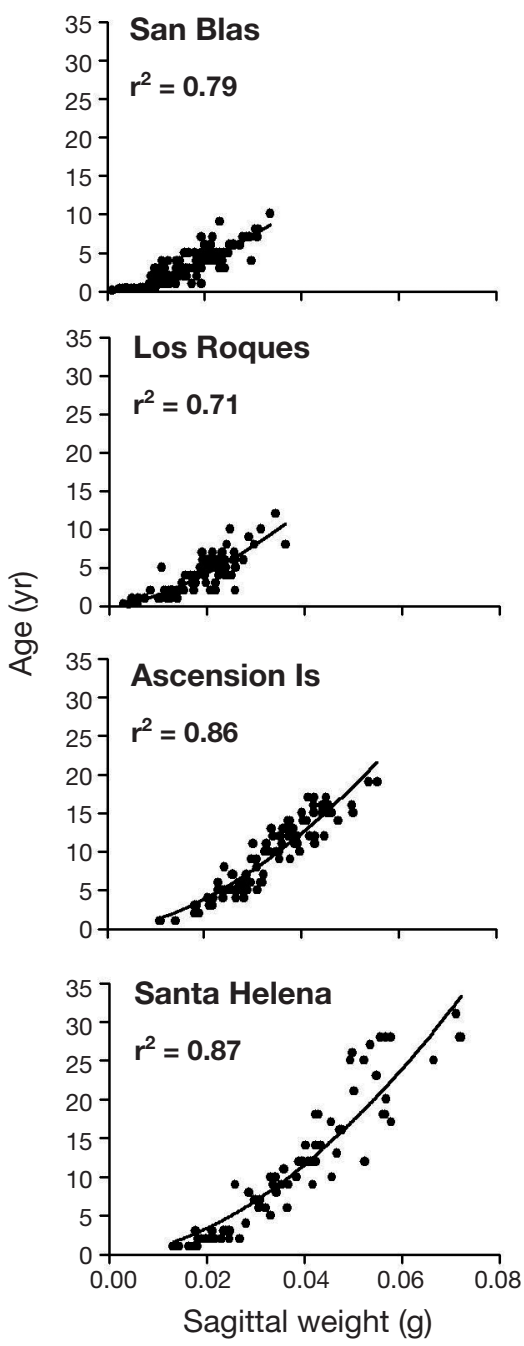
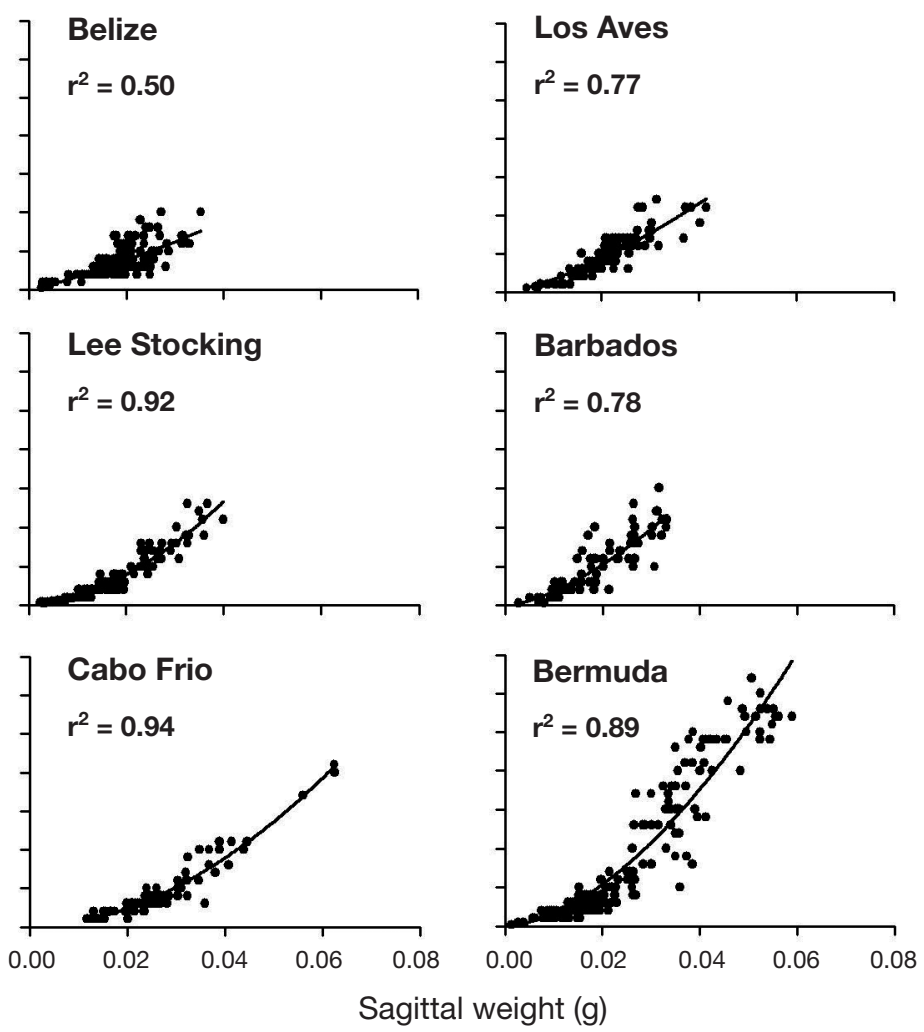

Fig. 3. Acanthurus bahianus. Otolith growth trajectories: power functions of age vs. sagittal weight in 10 populations 
ries among locations was so great that the $95 \%$ confidence regions of the growth curves of different populations overlapped in only 2 of 45 possible location-pairs (Fig. 5).

Longevity, mortality, survivorship and population age structure. Maximum longevity, which varied from 10 yr at Panama to 32 yr at Bermuda, was strongly inversely related to MST $\left(\mathrm{r}^{2}=0.94\right)$ (Fig. 6A). Estimation of extreme statistics, such as maximum age, is highly sensitive to variation in sample size. However, the lack of a correlation $(r=0.26, p=0.46)$ between sample size (of fish $2+$ yr in each population) and maximum age of Acanthurus bahianus indicates that this latitudinal pattern of variation in longevity is not a sampling artefact.

Log-linear regressions of mortality rates at the different locations (Fig. 7B) areas follows: Belize: $y=5.06 x^{-0.48}$; Panama: $y=4.12 x^{-0.39}$; Las Aves: $y=$ $4.01 x^{-0.30}$; Los Roques: $y=3.35 x^{-0.27}$; Bahamas: $y=$ 3.41 $x^{-0.26}$; Barbados: $y=2.85 x^{-0.18} ;$ Bermuda: $y=$ $2.41 x^{-0.16} ;$ Brazil: $y=2.36 x^{-0.13}$; Ascension: $y=$
$2.54 x^{-0.07} ;$ St. Helena $y=1.66 x^{-0.05}$. Regression slopes were compared using ANCOVA (see Zar 1999): those of Ascension, Cabo Frio, Bermuda and St. Helena were each statistically different from both Belize and Panama at $\mathrm{p}<0.05$; all remaining combinations of locations were not significantly different. The average annual rate of survivorship was also inversely related to MST, although less strongly so than longevity $\left(\mathrm{r}^{2}=0.67\right.$, Fig. 6B).

An ANCOVA comparing the longevity/MST relationships at the 3 mid-ocean islands (Ascension, Bermuda and St. Helena) to those at the 7 remaining sites (Fig. 6A) detected no statistically significant differences in either slopes or intercepts of these 2 relationships: islands: $y=103.9-3.3 x$; other: $y=86.1-$ $2.7 x$; comparison of slopes $-t=0.72, \mathrm{p}=0.50$; comparison of intercepts $-t=2.18, \mathrm{p}=0.065$. However, sample sizes are small, and the difference in the intercepts is only marginally non-significant; hence the power of this test is low.

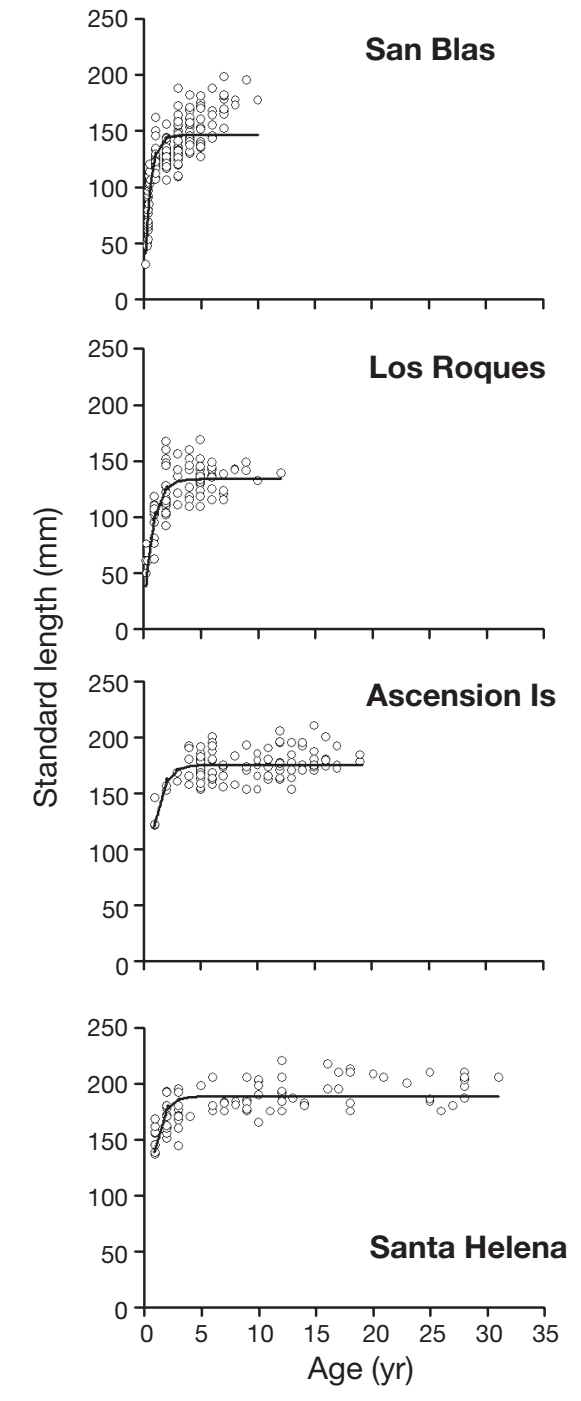

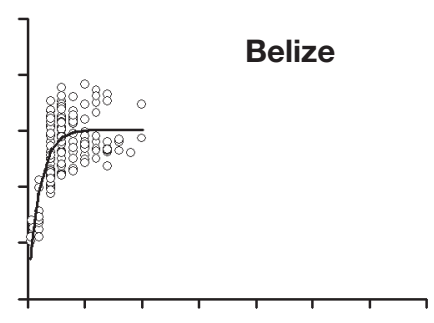
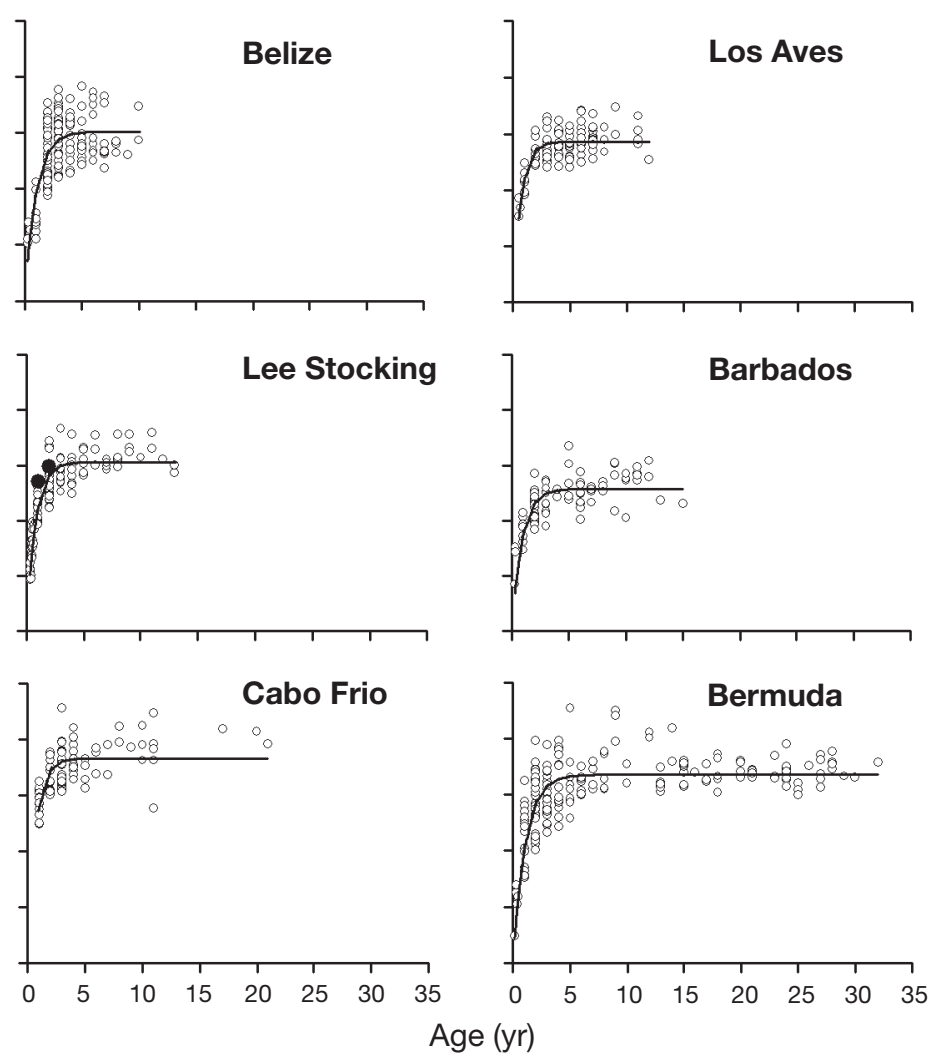

Fig. 4. Acanthurus bahianus. Von Bertalanfy growth curves for populations at 10 localities. ( $\bullet$ in Lee Stocking curve represent the 2 individuals used in tetracycline tag/recapture experiment. 
Table 2. Acanthurus bahianus. Demographic information on populations at 10 locations. Intercepts of growth functions were constrained to $0 \mathrm{~mm}$. Sites arranged in descending order of mean sea surface temperature. Size at age (standard length, SL) is from von Bertalanffy growth functions (VBGF). See 'Materials and methods' for determination of survivorship. na: not applicable

\begin{tabular}{|c|c|c|c|c|c|c|c|c|c|c|}
\hline \multirow[t]{2}{*}{ Locality } & \multirow[t]{2}{*}{$\mathrm{n}$} & \multirow{2}{*}{$\begin{array}{c}\text { Size range } \\
(\mathrm{SL}, \mathrm{mm})\end{array}$} & \multirow[t]{2}{*}{$L_{\infty}$} & \multirow[t]{2}{*}{$K$} & \multirow{2}{*}{$\begin{array}{c}\mathrm{r}^{2} \\
(\mathrm{VBGF})\end{array}$} & \multirow{2}{*}{$\begin{array}{c}\text { Max. } \\
\text { age (yr) }\end{array}$} & \multirow{2}{*}{$\begin{array}{c}\text { Survivorship } \\
\mathrm{yr}^{-1}\end{array}$} & \multicolumn{3}{|c|}{ Mean SL ( $\left.\% L_{\infty}\right)$ at: } \\
\hline & & & & & & & & $1 \mathrm{yr}$ & $2 \mathrm{yr}$ & $3 \mathrm{yr}$ \\
\hline \multicolumn{11}{|l|}{ Belize } \\
\hline Outer reef & 67 & $51-160$ & 137.9 & 0.67 & 0.80 & 10 & na & 53.7 & 82.0 & 91.1 \\
\hline Inner reef & 78 & $70-191$ & 162.6 & 1.17 & 0.35 & 10 & na & 60.9 & 93.4 & 97.0 \\
\hline Total & 145 & $51-191$ & 151.0 & 1.01 & 0.47 & 10 & 0.52 & 63.4 & 86.8 & 95.2 \\
\hline Panamá & 175 & $31-198$ & 146.3 & 2.10 & 0.68 & 10 & 0.61 & 87.8 & 98.6 & 99.9 \\
\hline Barbados & 94 & $42-167$ & 128.5 & 1.14 & 0.58 & 15 & 0.82 & 67.9 & 89.7 & 96.7 \\
\hline Los Roques & 86 & $50-169$ & 134.0 & 1.36 & 0.59 & 12 & 0.73 & 74.5 & 93.5 & 98.4 \\
\hline Las Aves & 108 & $76-174$ & 143.2 & 1.43 & 0.51 & 12 & 0.70 & 76.1 & 94.3 & 98.7 \\
\hline Bahamas & 124 & $46-183$ & 152.8 & 1.26 & 0.58 & 13 & 0.74 & 72.2 & 92.2 & 97.8 \\
\hline Ascension & 109 & $121-210$ & 175.4 & 1.22 & 0.29 & 19 & 0.93 & 70.5 & 91.3 & 97.4 \\
\hline Cabo Frio & 93 & $124-228$ & 182.8 & 1.43 & 0.48 & 21 & 0.87 & 76.0 & 94.2 & 98.6 \\
\hline \multicolumn{11}{|l|}{ Bermuda } \\
\hline Outer reef & 99 & $115-225$ & 171.8 & 0.63 & 0.27 & 32 & na & na & na & na \\
\hline Inner reef & 81 & $24-227$ & 161.5 & 1.15 & 0.55 & 6 & na & na & na & na \\
\hline Total & 180 & $24-227$ & 167.8 & 0.94 & 0.56 & 32 & 0.94 & 60.8 & 84.6 & 94.0 \\
\hline St. Helena & 88 & $137-220$ & 188.4 & 1.40 & 0.40 & 31 & 0.95 & 75.3 & 93.9 & 98.5 \\
\hline
\end{tabular}

The age-structures of adult populations at the 3 isolated oceanic islands (Ascension, Bermuda and St. Helena) (Fig. 7A) were distinctly multimodal, with peaks of abundance at roughly 7 to $10 \mathrm{yr}$ intervals. There also were weaker indications of multiple modes at 4 other locations (Cabo Frio, Barbados, Los Roques and Las Aves), but not at Belize, the Bahamas or Panamá.

Maximum and asymptotic size. Both maximum and asymptotic size varied considerably among locations: asymptotic size by 1.44-fold in length and $\sim 3$-fold in weight (as calculated from $L_{\infty}$ and a length/weight curve of all fish), and maximum size by 1.36 -fold in length and 2.5-fold in weight (Table 2). Both $L_{\infty}$ and maximum length were inversely related to MST across our set of study areas (Fig. 8A), although these relationships were notably weaker than that between longevity and MST (Fig. 6A).

Growth rates. There was a statistically significant inverse relationship between MST and instantaneous growth rate at $1 \mathrm{yr}$, and a marginally non-significant relationship at 6 mo (Fig. 9A). The slope of the MST/ growth-rate relationship declined with increasing age, and at 2 yr growth rate was unrelated to MST (Fig. 9A). Variation in $L_{\infty}$ among our 10 localities was positively related to growth rates at both 6 mo and 1 yr (Fig. 9B), with a lower slope to the relationship at $1 \mathrm{yr}$. At $2 \mathrm{yr}$, when fish had reached $\sim 90 \%$ of asymptotic length (see below), growth rates had changed among localities to the extent that they no longer predicted that length (Fig. 9B). However, the pattern of growth trajectories varied among localities such that a similar percentage of $L_{\infty}$ was achieved at 1, 2 and 3 yr at each site, regard- less of MST (Table 2, Fig. 8B). Average length at $2 \mathrm{yr}$, or 6 to $20 \%$ (average $13.6 \%$ ) of maximum longevity, was at least $90 \%$ of asymptotic length, and average length at 3 yr was at least $94 \%$ of asymptotic length in all cases (Table 2).

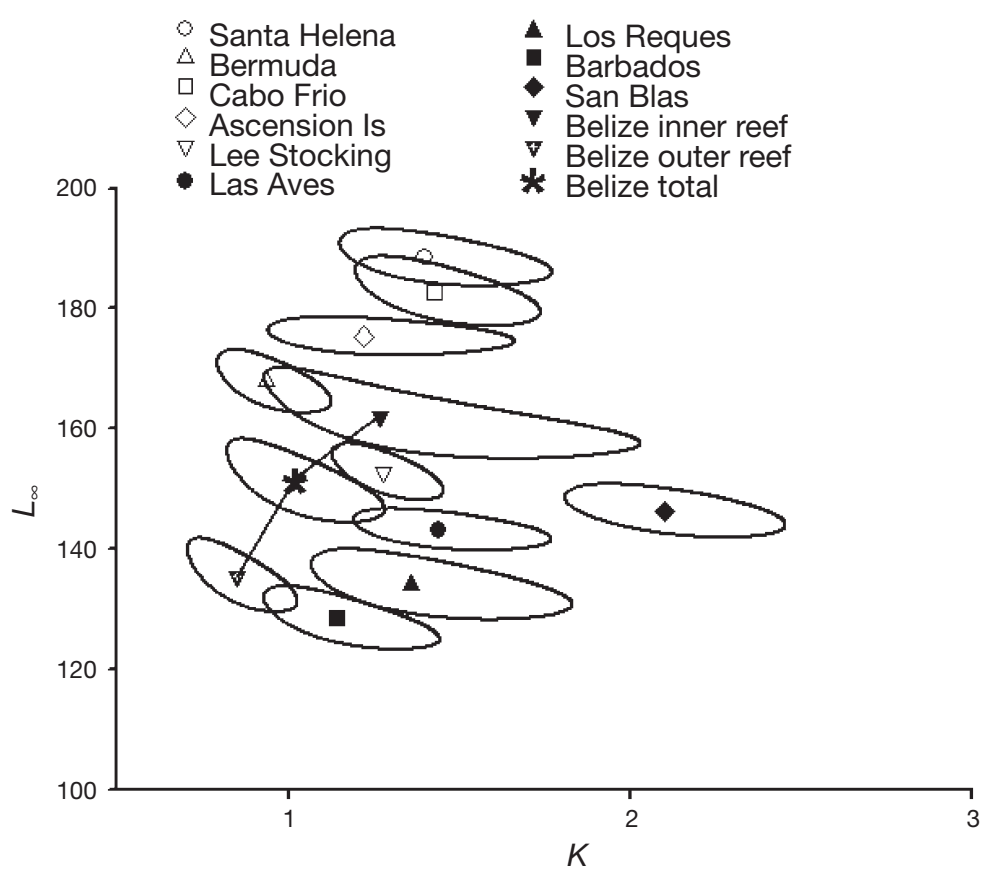

Fig. 5. Acanthurus bahianus. Variation in structure of von Bertalanffy growth curves among 10 sites and in 2 habitats (joined by lines) at Belize, 95\% confidence regions around least squares estimates of $K$ and $L_{\infty}$ are shown (after Kimura 1980) 


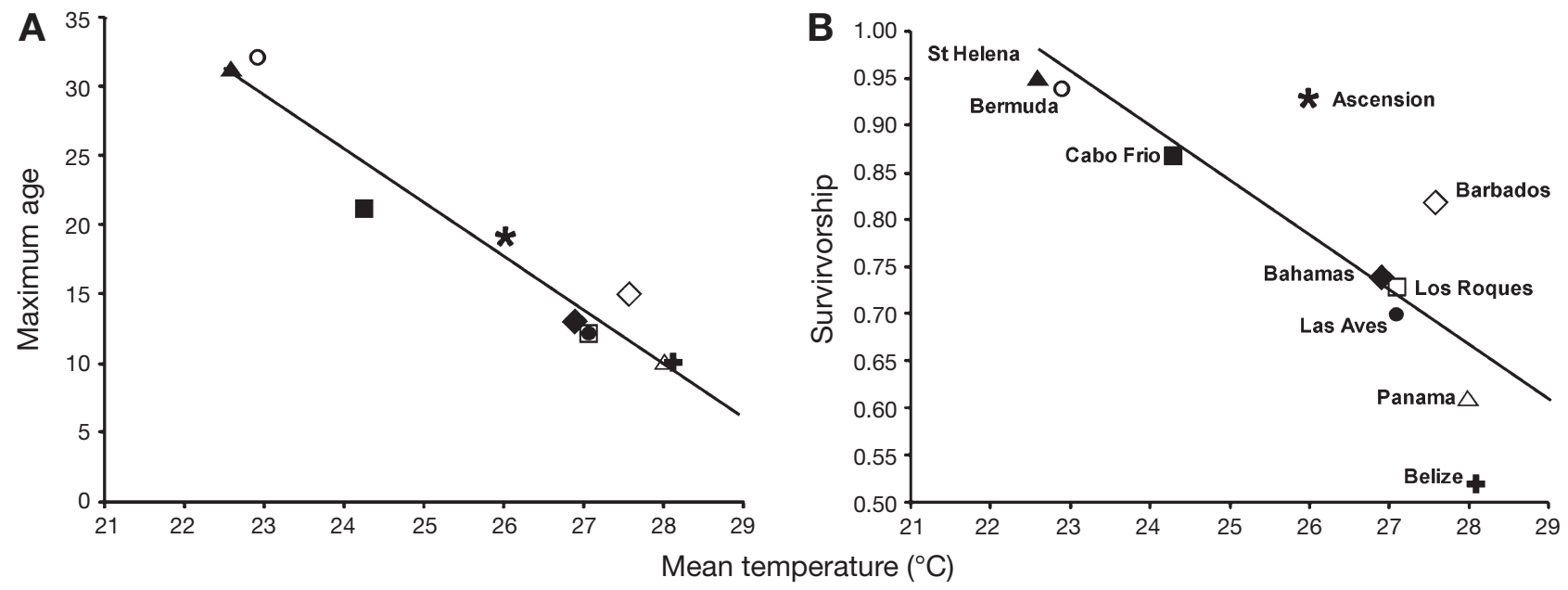

Fig. 6. Acanthurus bahianus. Regressions of longevity and survivorship vs. mean sea surface temperature at 10 sites. (A) Maximum longevity $\left(y=-3.87 x+118.25, \mathrm{r}^{2}=0.94, \mathrm{p}<0.01\right)$. (B) Average annual survivorship $\left(y=-0.058 x+2.3, \mathrm{r}^{2}=0.67, \mathrm{p}<0.01\right)$
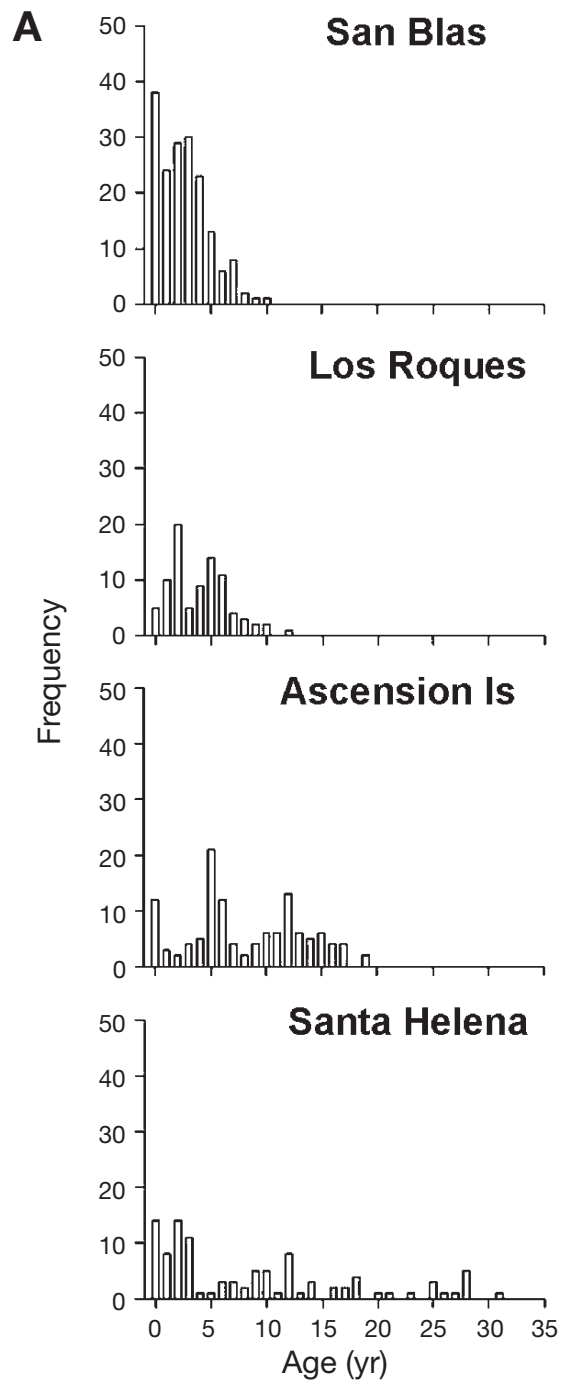
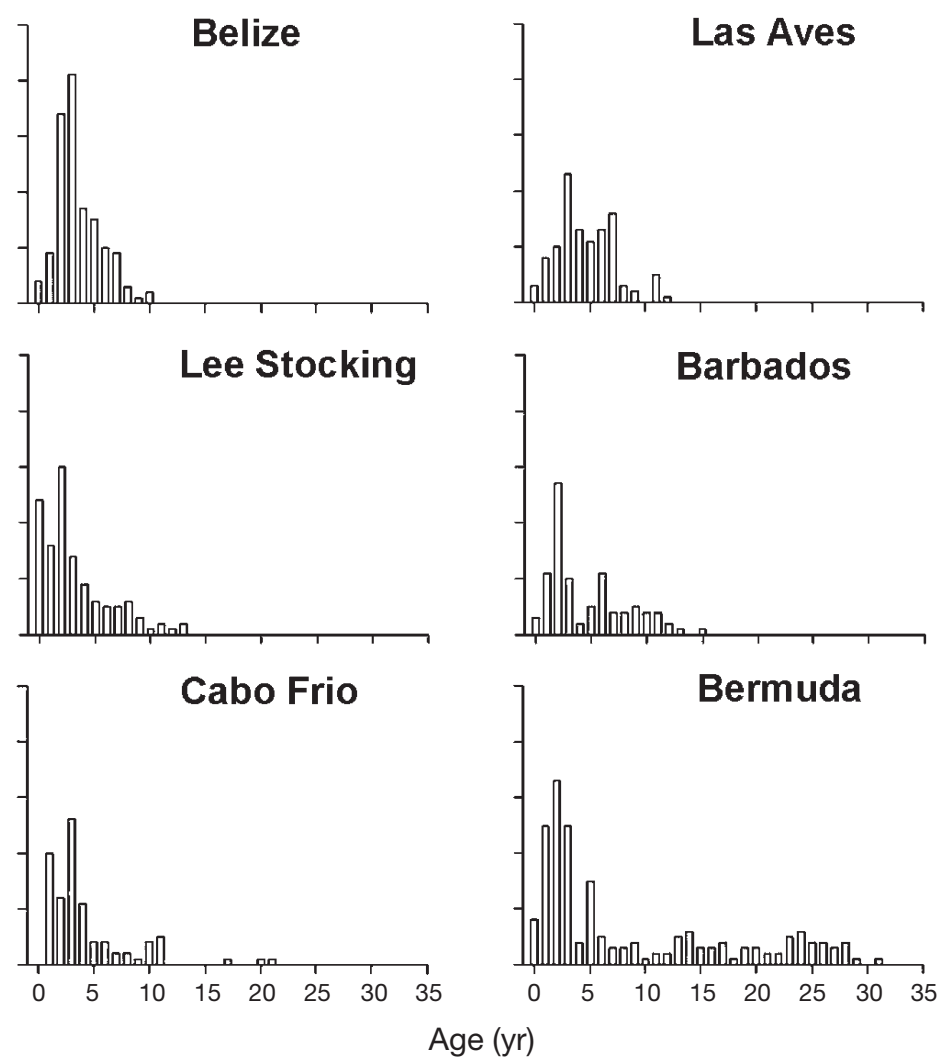

Fig. 7. Acanthurus bahianus. (A) Age-frequency (\%) distributions and (B) log-linear regressions of annual annual mortality rates of 10 populations 


\section{Local habitat variation in demography}

Bermuda. At Bermuda fish reached the same maximum sizes on inner and outer reefs, although asymptotic size was marginally larger on the outer reefs (Fig. 10A). Among the numerous large fish collected in both habitats, no individuals older than 6 yr were found on inner reefs, whereas most collected on outer reefs ranged from 7 to $32 \mathrm{yr}$ (Fig. 10A). Fish smaller than $\sim 120 \mathrm{~mm}$ SL were collected only on inner reefs, and we observed no juveniles on the outer reefs: 4 yr monitoring of recruitment of this species in different habitats at Bermuda by J. Pitt has shown that pelagic juveniles rarely recruit to outer reefs. Although confidence regions of the somatic growth curves for these 2 habitats (not included here) do not overlap, we are cautious about concluding that inner-reef-fish grow faster: there is considerable scatter in age-at-size data among age classes found in both habitats (Fig. 10A), the $\mathrm{r}^{2}$ value for
1 curve is quite low (Table 2), and small fish were obtained in only 1 habitat. The degree of difference in otolith growth curves for the 2 habitats (Fig. 11A) roughly parallels that between the somatic growth curves.

Belize. The situation at Belize contrasts strongly with that at Bermuda. Juveniles and adults occurred on both inner and outer reefs. Although there were no differences in maximum longevity (10 yr) between the 2 habitats, inner reef-fish reached a substantially larger asymptotic length which, based on a length/weight relationship derived from our entire data set, is equivalent to $\sim 50 \%$ greater weight. Inner reef-fish not only grew faster than outer reef-fish in absolute terms, but also reached a slightly greater percentage of asymptotic length at 1, 2 and 3 yr (Fig. 10B, Table 2). In fact, differences between average growth trajectories in the 2 habitats at Belize were so large that they spanned most of the range of variation found among the remaining 6 locations in the NW Atlantic (Fig. 5).
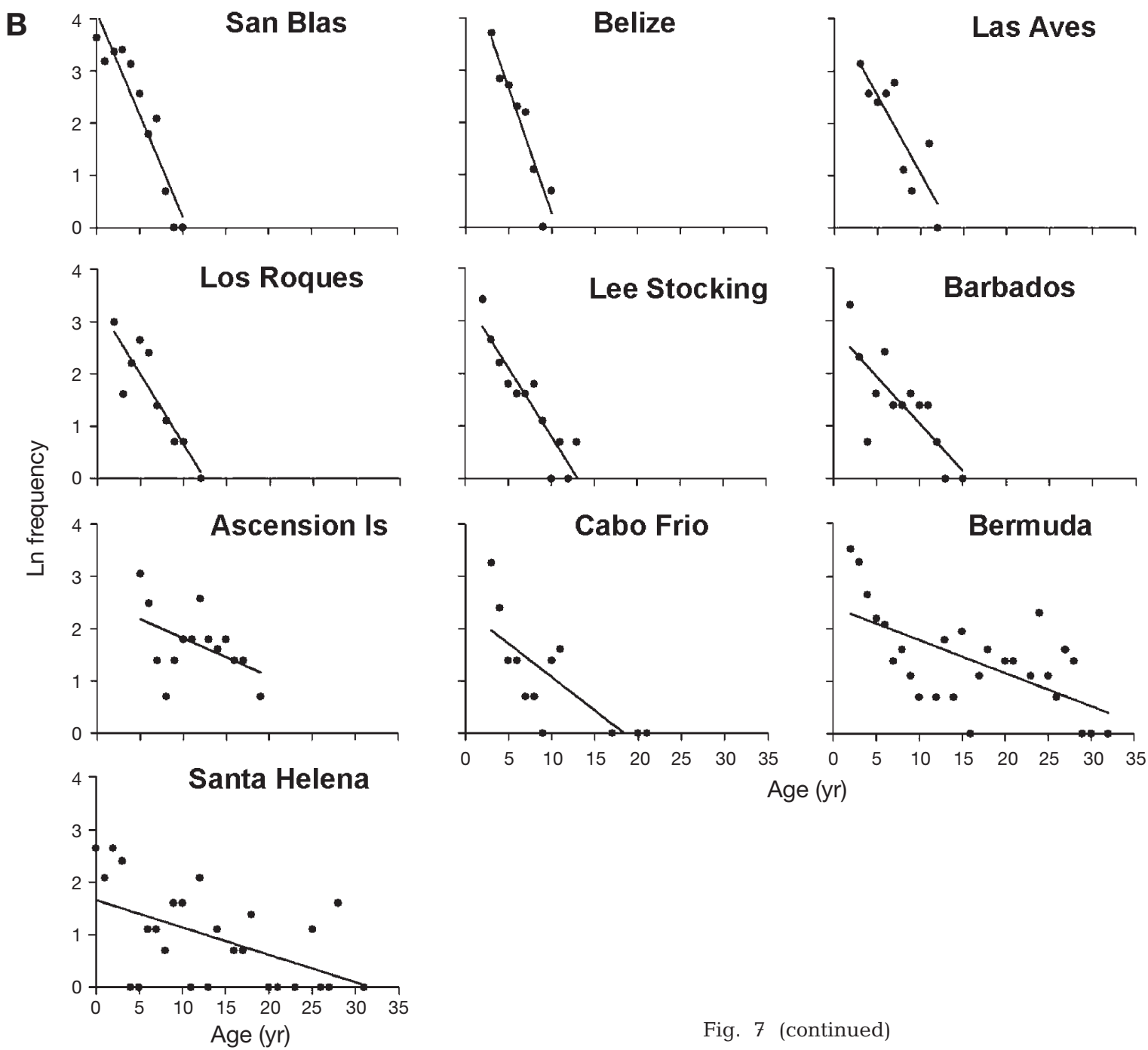

Fig. 7 (continued) 

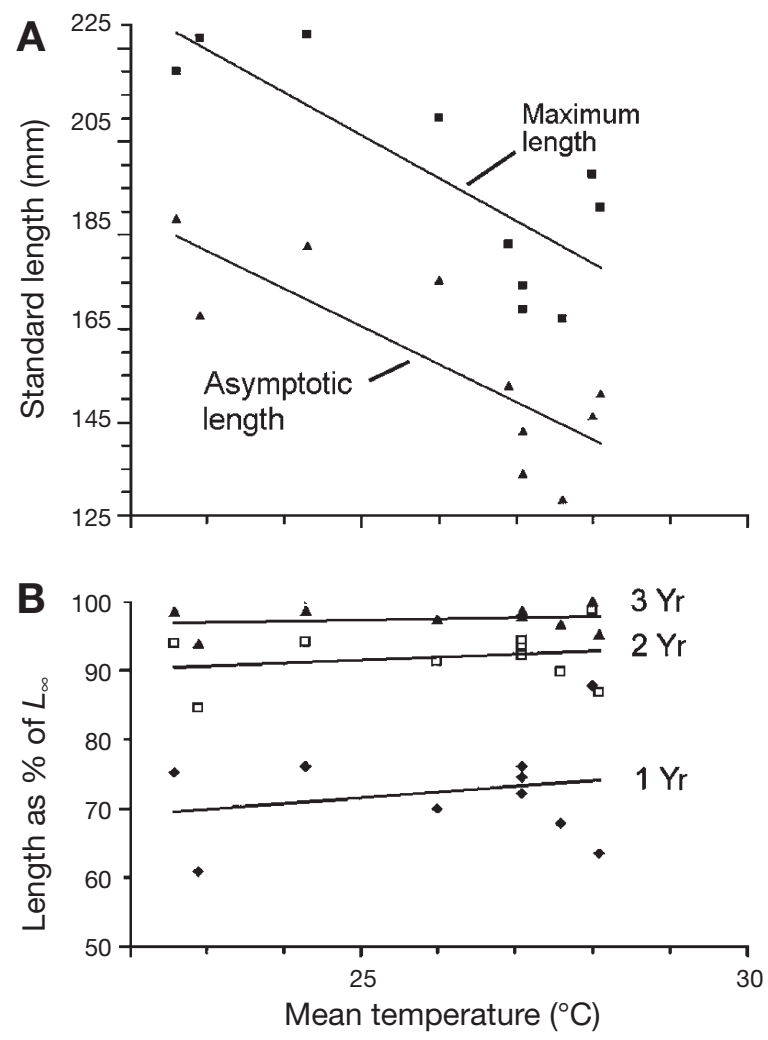

Fig. 8. Acanthurus bahianus. Relationships between length and size-at-age and mean sea surface temperature. (A) Absolute size: asymptotic length $\left(y=436.0-9.18 x, \mathrm{r}^{2}=0.64, \mathrm{p}<\right.$ $0.01)$, maximum length $\left(y=367.0-8.06 x, \mathrm{r}^{2}=0.65, \mathrm{p}<0.01\right)$; (B) relative size (mean length as \% of $L_{\infty}$ ) at different ages: at $1 \mathrm{yr}\left(y=51.6+0.8 x, \mathrm{r}^{2}=0.05, \mathrm{~ns}\right), 2 \mathrm{yr}(y=81.2+0.41 \mathrm{x}$, $\left.\mathrm{r}^{2}=0.04, \mathrm{~ns}\right)$ and $3 \mathrm{yr}\left(y=92.9+0.18 x, \mathrm{r}^{2}=0.04, \mathrm{~ns}\right) ; \mathrm{ns}=$ not significant

These habitat differences in rates of somatic growth were reflected in differences in otolith growth trajectories at Belize, with otoliths of inner reef-fish growing faster and reaching a larger maximum size (Fig. 11B). It is also noteworthy that there are outliers to the curves for both otolith- and somatic growth among fish from both habitats (Figs. 10B \& 11B).

\section{DISCUSSION}

The ocean surgeonfish, a relatively small member of its genus (see Choat \& Robertson 2002), and the smallest of the 3 west Atlantic species, displays the most rapid growth to asymptotic size of any of 17 Atlantic and Indo-Pacific acanthurids examined by Choat \& Robertson (2002, see their Fig. 4). Growth trajectories of Acanthurus bahianus varied considerably among locations, including neighbouring reefs at similar latitudes and with similar sea temperatures. This variation, which was so great that confidence regions of
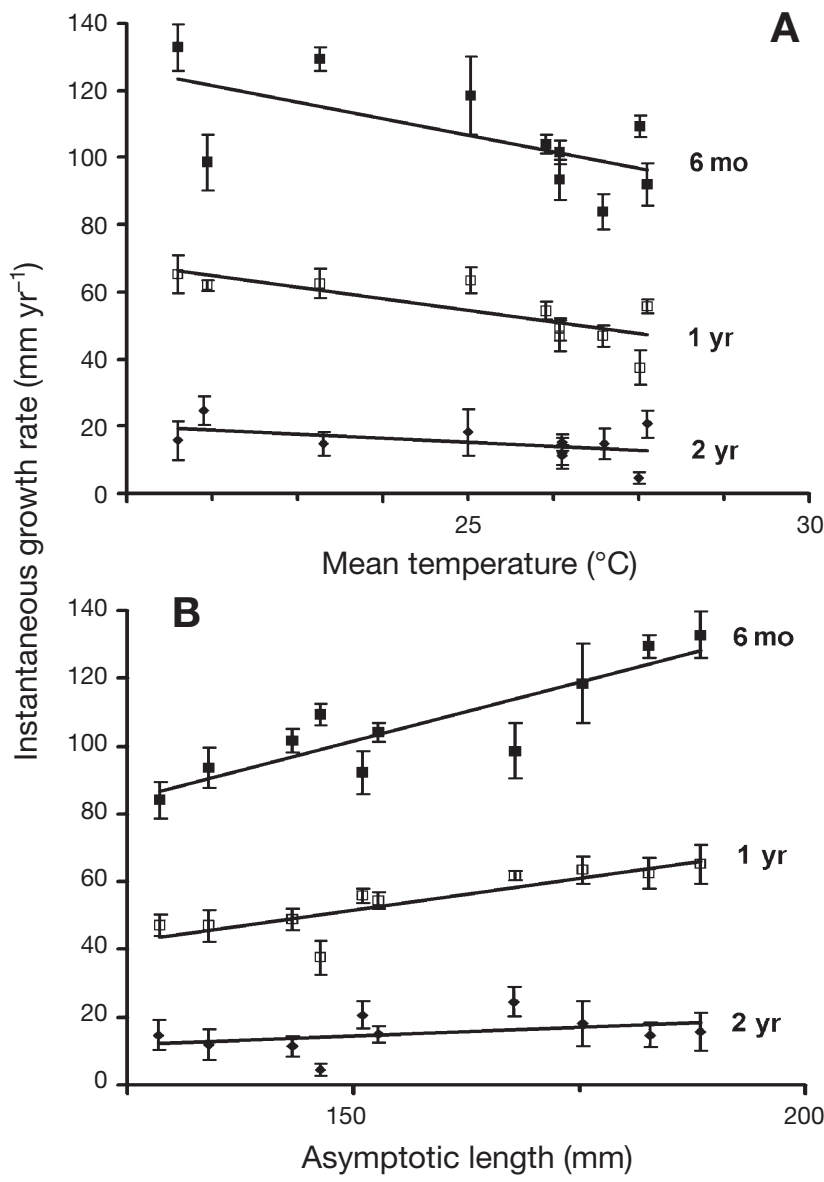

Fig. 9. Acanthurus bahianus. Instantaneous rates of growth at different ages vs. mean sea surface temperature and terminal size at 10 sites. Bars indicate $95 \%$ confidence intervals of growth estimates. (A) Growth rates vs. temperature at 6 mo $\left(y=234.1-4.90 x, r^{2}=0.39, p=0.06\right), 1$ yr $(y=143.4-3.42 x$, $\left.\mathrm{r}^{2}=0.59, \mathrm{p}<0.01\right)$ and $2 \mathrm{yr}\left(y=48.0-1.26 \mathrm{x}, \mathrm{r}^{2}=0.23, \mathrm{~ns}\right)_{i}$ (B) growth rates vs. asymptotic length at 6 mo $(y=0.69 x-$ $\left.2.15, \mathrm{r}^{2}=0.77, \mathrm{p}<0.01\right), 1 \mathrm{yr}\left(y=0.37 x-4.44, \mathrm{r}^{2}=0.71\right.$, $\mathrm{p}<0.01)$ and $2 \mathrm{yr}\left(y=0.10 x-0.66, \mathrm{r}^{2}=0.14, \mathrm{~ns}\right)$

VBGFs overlapped in $<5 \%$ of the location-pair combinations among our 10 populations, is the strongest yet documented for a tropical reef-fish (see Newman et al. 1995, Luckhurst et al. 2000, Meekan et al. 2001, Choat \& Robertson 2002, Gust et al. 2002, Krizter 2002, Choat et al. 2003, Williams et al. 2003, Ackerman 2004).

Rocha et al. (2002) found a substantial genetic break between the Caribbean (Bermuda was not sampled in that study) and Brazil plus central Atlantic groups of populations of Acanthurus bahianus. The fact that the latter include 3 of our 4 low-temperature sites raises the possibility of confounding environmental and genetic effects on geographic variation in the demography of this species. However, a subsequent analysis by L. A. Rocha (pers. comm. 2003) found no genetic difference between the Bermuda and Caribbean popula- 


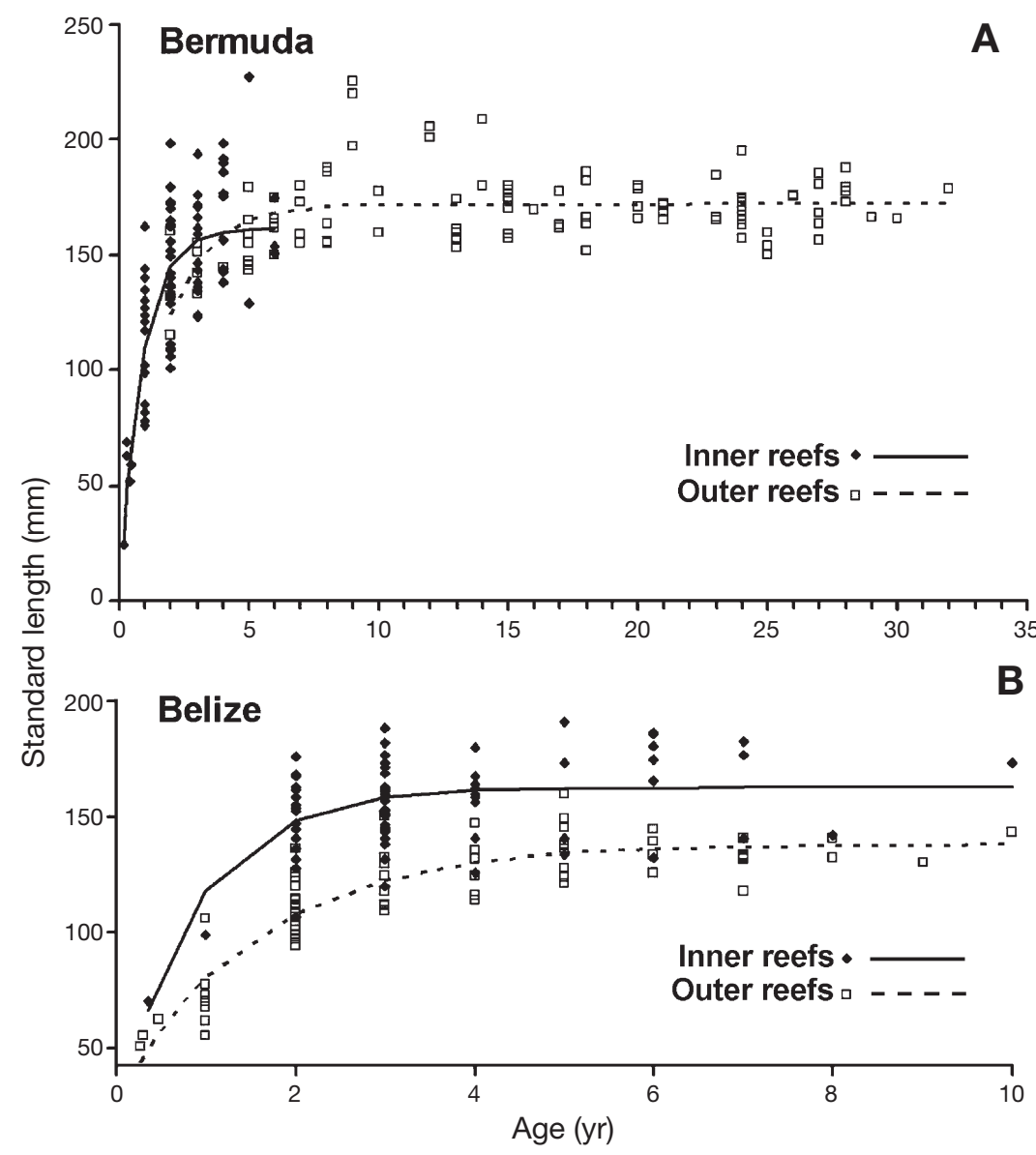

Fig. 10. Acanthurus bahianus. Somatic growth in 2 habitats at each of 2 sites. (A) Bermuda, and (B) Belize, showing von Bertalanffy growth functions
Pitt pers. obs.), which are lacking on outer reefs at Bermuda. The simplest explanation for the lack of juveniles and abundance of adults on the outer reefs, the slightly greater growth rates and slightly smaller asymptotic size of inner reef-fish, and the much greater age achieved by outer reef-fish, is that fish recruit to inner reefs and grow rapidly there till they near asymptotic size. Then, when 2 to 6 yr old, they relocate permanently to outer reefs, where they spend the remainder of their lives (up to $32 \mathrm{yr}$ ).

At Belize, in contrast, inner-reef-fish grow much faster and reach a substantially larger asymptotic size ( $50 \%$ greater in weight terms) than outer reeffish, but both habitats receive recruits, and fish in both habitats achieve the same longevity (10 yr). Thus fish evidently commonly complete the entire benthic stage of their lives in both habitats, but have very different growth characteristics in each. Growth-curve outliers in both habitats may arise in 2 ways. First, Acanthurus bahianus is known to relocate over distances equivalent to those separating inner and outer reefs at Belize (see Munro 2000), and may do so in both directions between the 2 habitats. Second, there may be small scale spatial variation in conditions for growth within both habitat types.

tions of $A$. bahianus. Since the range of temperature regimes and longevity, size and growth characteristics of Brazil and central Atlantic populations are largely encompassed by those among the NW Atlantic sites and populations, it seems unlikely that genetic differences present serious confounding effects in our analysis of geographic variation in the demography of this species.

\section{Local habitat variation in demography}

There were major habitat differences in the demography of the ocean surgeonfish at both Belize and Bermuda. Further, despite broad comparability of the pairs of habitats sampled at the 2 sites, habitat variation in demography followed a different pattern at each site. While inner reef-fish may grow slightly faster than outer reef-fish at Bermuda, there is little or no difference in terminal size in those 2 habitats. Pelagic juveniles of Acanthurus bahianus settle in sheltered shallow habitats (Robertson 1988, 1992, J.
At Belize and Bermuda the 2 habitats we examined are quite different structurally, well separated, and extensive. Associated differences in population composition of Acanthurus bahianus that stimulated separate sampling in each were quite obvious. At other localities, either the range of habitats is much smaller (e.g. Ascension and St. Helena only have narrow rocky shorelines) or different habitat types are more patchily distributed and intergrade more continuously, reducing the potential for strong, widespread inter-habitat differences like those at Belize and Bermuda. Our collections at such locations produced a single population sample that incorporates the local range of variation in demographics, but does not allow detailed analyses of small scale habitat effects.

Local habitat variation in growth patterns is not unusual among reef-fishes. Reverse seasonal patterns of growth and reproduction of a Caribbean parrotfish in 2 habitats reflect differing effects of weather on food availability in those habitats (Clifton 1995). Differences in terminal size and longevity of west 


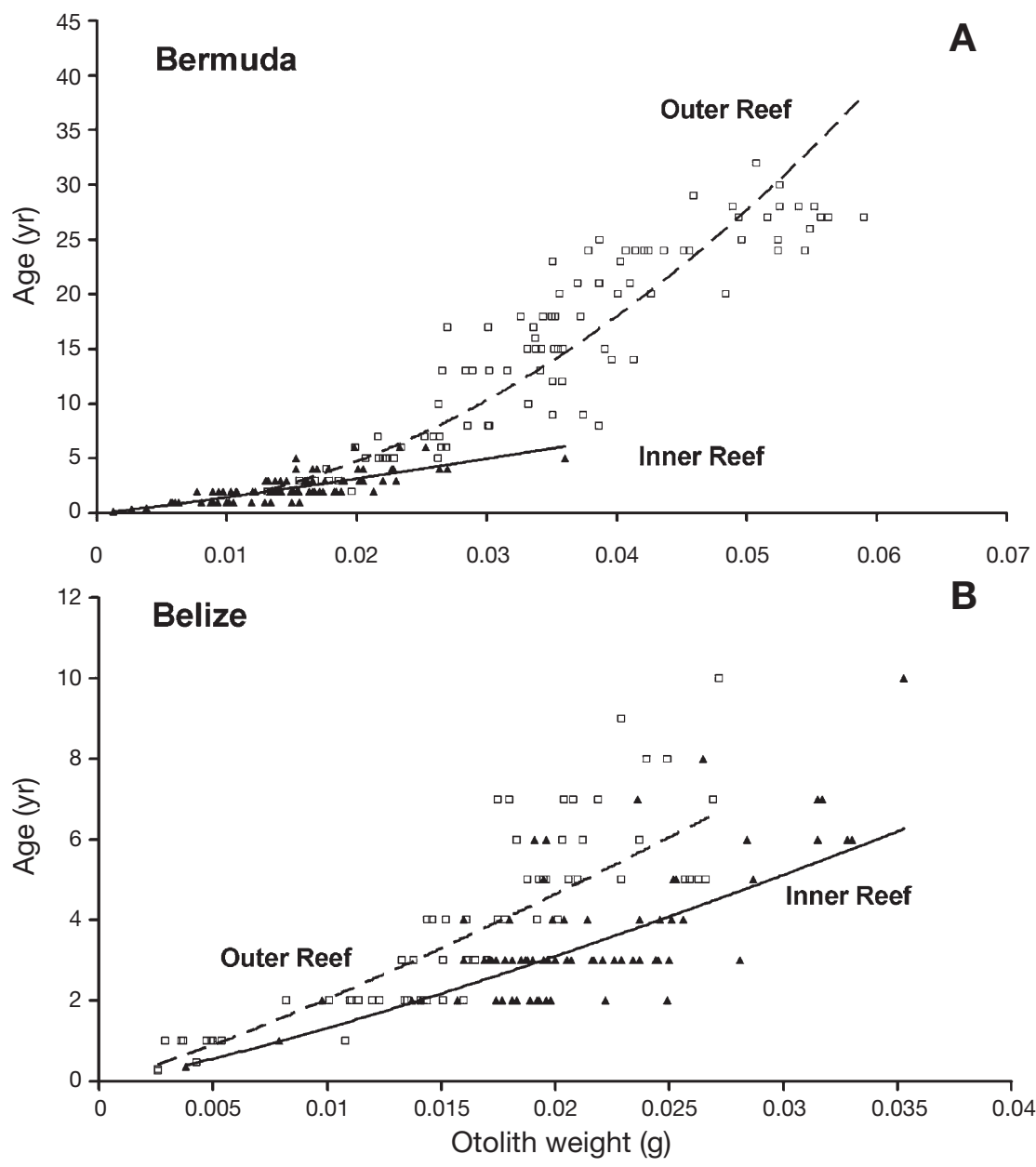

Fig. 11. Acanthurus bahianus. Otolith growth trajectories in 2 habitats at 2 sites. (A) Bermuda, outer reef: $y=9153.3 x^{1.94}, \mathrm{r}^{2}=0.87$; inner reef: $y=253.2 x^{1.12}, \mathrm{r}^{2}=0.76$.

(B) Belize, outer reef: $y=491.8 x^{1.19}, \mathrm{r}^{2}=0.84$; inner reef: $y=390.3 x^{1.24}, \mathrm{r}^{2}=0.63$

\section{Geographic variation in demography}

Acanthurus bahianus exhibits the same basic latitudinal gradient in 3 demographic characteristics: growth rates, terminal size and longevity are all inversely related to temperature. However, relationships between temperature and both growth and size are weaker than that between temperature and longevity, and growth and terminal size are more strongly interlinked than either is with longevity. Throughout this species' large latitudinal range growth occurs for a relatively short and fixed period (2 to $3 \mathrm{yr}$ ) and then effectively ceases, despite the existence of considerable variation in maximum longevity. Terminal size at the end of the growth period may largely be determined by the rate of that growth, which is strongly affected by habitat conditions (on both small and large spatial scales) as well as latitude. Based on the size at which fish mature at Jamaica ( $45 \%$ of maximum length: Reeson 1983) and the rapid growth we found in all populations, maturity seems likely to occur within $1 \mathrm{yr}$ in most cases. Robertson et al. (2005) found no evidence of consistent effects of fishing on geographic variation in the longevity, survivorship, size and abundance of this species. Hence here we assume that the

Pacific parrotfishes and surgeonfishes on lagoonal vs. outer reefs have been attributed to effects of differences in shelter availability, abundances of predators and competitor densities (Gust et al. 2002). Mobility of fish also affects the extent of small scale (neighbouring reefs) variation in demography vs. larger scale variation (Williams et al. 2003). Hence considerable small (kilometres) to medium (tens of kilometres) scale variation in demography is likely to be the rule for reef-fishes, particularly among more sedentary species, and a diversity of patterns and causal mechanisms are likely to be involved. Local habitat variation in the demography of Acanthurus bahianus is as at least as great as that in any tropical reef-fish sampled to date. In fact variation in growth trajectories is sufficiently large at Belize that it spans most of the range of variation within an entire biogeographic region (the tropical NW Atlantic), a situation not previously described for other reef-fishes. demographic patterns we discuss have not been distorted by impacts of fishing.

Latitudinal increases in size are common among aquatic ectotherms (Atkinson 1994, Atkinson \& Sibly 1997), including tropical and subtropical reef-fishes (e.g. Cowen 1990, Gilligan 1991, Luckhurst et al. 2000, Choat \& Robertson 2002). Latitudinal variation in growth rates in fishes ranges from being directly (Atkinson 1996) to inversely related to temperature (Conover 1990, Garvey et al. 1998, Belk \& Houston 2002). Choat et al. (2003) found indications that, as with Acanthurus bahianus, growth of a Caribbean parrotfish (Sparisoma viride) is inversely related to temperature across a small latitudinal gradient. Inspection of data on latitudinal variation in growth trajectories of tropical Indo-Pacific reef-fishes in other studies (e.g. see Craig et al. 1999, Meekan et al. 2001, Choat \& Robertson 2002) reveals similar patterns. Thus this same latitudinal pattern of variation in growth and size 
(faster growth and larger terminal size at lower temperatures) occurs in different families of reef-fishes in various parts of the tropics.

The ocean surgeonfish has one of the largest latitudinal ranges of any Atlantic reef-fish. At the highlatitude limits of its range this species is abundant and exhibits strongly positive growth characteristics. This combination of features raises the question of the extent to which latitudinal growth patterns are involved in determining the latitudinal ranges of tropical reef-fishes: do species with large latitudinal ranges tend to have strong inverse temperature/growth gradients similar to that of Acanthurus bahianus? Do species found only in equatorial areas tend to be restricted to those areas because they have weaker inverse growth gradients or grow best at higher temperatures?

Inverse temperature gradients in geneticallycontrolled growth capacity of temperate fishes, known as countergradient growth, are thought to represent a mechanism that compensates for reductions in the duration of growing seasons produced by low temperatures at high latitudes (Conover 1990, Conover \& Schultz 1995). The inverse relationship between growth and temperature in Acanthurus bahianus is consistent with countergradient growth. However, we cannot assume that it has a genetic basis because it is clear that local environmental effects, such as those at Belize, can influence growth and size almost as strongly as temperature appears to do. In species with countergradient growth, increased growth at high latitudes may arise either through a combination of increased food consumption and increased efficiency of food utilisation (Present \& Conover 1992, Billerbeck et al. 2000), or through increased growth-efficiency alone (Kokita 2004). In these cases, however, the role of latitudinal variation in food supplies in the wild has not been investigated. Our data indicate that food availability or some other habitat-related factor may play an important part in producing marked variation in growth and size of $A$. bahianus: at Belize differences in growth and terminal size of $A$. bahianus between 2 habitats a few kilometres apart are almost as great as differences between locations at the latitudinal (temperature) extremes within the NW Atlantic-Bermuda and Panama. Thus there is a real possibility that ecological factors such as food availability may be largely responsible for the latitudinal gradients of growth and size in A. bahianus.

In some temperate species that exhibit countergradient growth, the increased growth rate during the shortened growing season at high latitudes has little or no effect on latitudinal variation in either annual growth rates or terminal sizes (Conover 1990, 1992, Conover \& Schultz 1995, Belk \& Houston 2002). The latitudinal growth gradient in Acanthurus bahianus, however, is notably stronger than in those species: the annualised growth rate of the ocean surgeonfish increases with increasing latitude, and this growth gradient leads to all populations having the same relative growth rate and reaching asymptotic size at about the same age, even though this size increases strongly with increasing latitude. Latitudinal growth and size gradients may arise in some fishes because slow growth/small size is selectively favoured at low latitudes and large size/rapid growth at high latitudes (Billerbeck et al. 2000). The fact that rapid growth to a large size occurs in a high-temperature population of A. bahianus (at Belize) indicates that this is not the case with this species.

Countergradient growth may allow temperate species to cope with size-dependent winter mortality (Conover 1990, 1992, Schultz \& Conover 1997, 1999, Schultz et al. 1997). It seems reasonable to expect that broadly distributed tropical fishes would be exposed to greater winter stresses at the high-latitude limits of their ranges, where they are approaching their thermal tolerance limits. If the growth gradient in Acanthurus bahianus is also related to size-dependent winter mortality then rates of such mortality must be affected most strongly by terminal size and the minimisation of the time ( 2 to $3 \mathrm{yr}$ ) taken to achieve it, and the size that effectively counters such mortality must increase with increasing latitude.

In the ocean surgeonfish the relationship between temperature and longevity is the strongest $\left(r^{2}=0.94\right)$ of the 3 latitudinal demographic gradients. Life-history theory assumes that there is a tradeoff between longevity and reproduction, an assumption largely supported by field evidence (Roff 1992, Stearns 1992). In various NW Atlantic reef-fishes, reproduction generally become more strongly seasonal as latitude increases (Robertson 1991). Acanthurus bahianus evidently exhibits such a pattern: recruitment of pelagic recruits occurs year round at Panama $\left(9^{\circ} \mathrm{N}, \mathrm{MST} 28^{\circ} \mathrm{C}\right)$ (Robertson \& Kaufmann 1998: data on $17 \mathrm{yr}$ recruitment), but is restricted to only 6 mo of the year at Bermuda $\left(32^{\circ} \mathrm{N}, \mathrm{MST} 22.9^{\circ} \mathrm{C}\right)$, with a 4 mo long peak in activity (J. Pitt unpubl. data on 4 yr recruitment). At Puerto Rico $\left(18^{\circ} \mathrm{N}\right.$, MST $\left.25.6^{\circ} \mathrm{C}\right)$ reproduction appears to be limited to $\sim 5$ mo of the year (Colin \& Clavijo 1988: based on 1 yr observations of spawning). Increased longevity at higher latitudes could arise because shorter reproductive seasons lead to lower mortality costs of reproduction. The fact that fish in 2 habitats at Belize have the same longevity but very different growth and size characteristics is consistent with longevity being determined by temperature mediated variation in this cost, of reproduction. If temperature determines that cost it should be the same in different subpopulations exposed to the same local temperature regime. 
Numerous interrelated questions about variation in the life-history characteristics of Acanthurus bahianus remain to be answered before we understand the proximate and ultimate mechanisms involved in producing the latitudinal gradients in size, growth, longevity and survivorship we describe here:

- Reproduction: how do the seasonality of reproduction and annual and lifetime reproductive output vary latitudinally? How do age and size at maturity vary in relation to asymptotic size, both latitudinally and between local subpopulations with different growth characteristics? For example, is rapid achievement of large terminal size at higher latitudes associated with delayed maturity?

- Latitudinal variation in growth and size: how does the seasonality of growth vary with latitudinal change in temperature regimes? How are latitudinal gradients in annual growth and terminal size affected by temperature per se, by variation in food availability and by genetically controlled variation in growth efficiency?

- Habitat variation in growth and size: what is the ecological basis of strong habitat variation in growth and size at Belize? Do latitudinal variation and local habitat variation in growth and size have the same ecological basis?

- Overwintering mortality: is size-dependent winter mortality a problem at high-latitude sites and, if so, how do rates of mortality relate to size achieved by the first winter, and to asymptotic size?

Is there an island-effect on longevity? Persistence of long-lived species is facilitated by the ability of their populations to 'store' influxes from high-recruitment years, which tide them over periods of poor recruitment (see Warner \& Chesson 1985). The degree of isolation of a population might be expected to affect selection for variation in demographic characteristics, with increased longevity at isolated islands buffering populations against recruitment failures (Meekan et al. 2001, Robertson 2001). Acanthurus bahianus is relatively long-lived at the 3 oceanic islands, and the strongly multimodal age structures of populations at those islands suggest strong fluctuations in recruitment. Although the strong inverse relationship between longevity and temperature in A. bahianus appears to account for this insular pattern, our test is relatively weak; a better one would involve islands in both warm and cool areas.

Acknowledgements. Logistical support was provided by the Bermuda Biological Station for Research (through an S. L. Wright fellowship to D.R.R.); the Caribbean Marine Research Centre at Lee Stocking Island; the Bellairs Marine Laboratory at Barbados; the Dos Mosquises research station of the Fundación Científica Los Roques and the Departamento de Biología de Organismos of the Universidad de Simon Bolivar,
Venezuela; the Smithsonian Institution's Caribbean Coral Reef Ecosystems (CCRE) laboratory at Carrie Bow Cay (Belize), and San Blas laboratory in Panamá; Carlos Ferreira at the Instituto de Estudos do Mar Almirante Paulo Moreira (IEAPM) at Cabo Frio; the US Airforce (at Ascension Island) and the Government of St. Helena. Research permits were issued by the Fisheries Departments of Bermuda, Belize and the Bahamas; the Instituto Nacional de Parques (INPARQUES) at Los Roques and the Instituto Nacional de Pesca y Acuicultura (INAPESCA) at Venezuela; the Kuna General Congress and the Government of Panamá; the Administrator at Ascension and the Governor of St. Helena. Funding was though the Smithsonian Tropical Research Institute (to D.R.R.); Queensland Government/Smithsonian Institution collaborative grants (to D.R.R. and J.H.C.); the James Cook University and the Australian Research Council (to J.H.C.), and the Smithsonian's CCRE program (contribution no. 698) (to D.R.R. and J.H.C.), and an S. L. Wright Fellowship (to D.R.R.) from the Bermuda Biological Station for Research (contribution no. 1654). Field and laboratory assistance were given by D. Alvarado, D. Debrot, C. S. Ferriera, I. Hernandez, E. Peña, Luiz Rocha and M. von Wangelin. J. Kritzer developed the 'VBGF confidence region' macro. The paper benefited from criticism by 3 anonymous reviewers.

\section{LITERATURE CITED}

Ackerman JL (2004) Geographic variation in size at age of the coral reef fish, Thalassoma lunare (family Labridae): a contribution to life history theory. PhD thesis, James Cook University, Townsville

Atkinson D (1994) Temperature and organism size - a biological law for ectotherms? Adv Ecol Res 25:1-58

Atkinson D (1996) Ectotherm life-history responses to developmental temperature. In: Johnston IA, Bennett AF (eds) Animals and temperature: phenotypic and evolutionary adaptation. Cambridge University Press, Cambridge, p 183-204

Atkinson D, Sibly RM (1997) Why are organisms bigger in colder environments? Making sense of a life history puzzle. Trends Ecol Evol 12:235-239

Belk MC, Houston DD (2002) Bergmann's rule in ectotherms: a test using freshwater fishes. Am Nat 160:803-808

Billerbeck JM, Schultz ET, Conover DO (2000) Adaptive variation in energy acquisition and allocation among latitudinal populations of the Atlantic silverside. Oecologia 122: 210-219

Bullock LH, Murphy MD, Godcharles MF, Mitchell ME (1992) Age, growth and reproduction of jewfish, Epinephelus itajara in the eastern Gulf of Mexico. Fish Bull (Wash DC) 90:243-249

Bush PG, Ebanks GC, Lane ED (1996) Validation of ageing techniques for Nassau grouper (Epinephelus striatus) in the Cayman Islands. ICLARM Conf Proc 48:150-157

Cappo M, Eden P, Newman SJ, Robertson S (2000) A new approach to validation of periodicity and timing of opaque zone formation in the otoliths of eleven species of Lutjanus from the central Great Barrier Reef. Fish Bull (Wash DC) 98:474-488

Chapman MR, Kramer DL (1999) Gradients in coral reef fish density and size across the Barbados marine reserve boundary: effects of reserve protection and habitat characteristics. Mar Ecol Prog Ser 181:81-96

Choat JH, Axe LM (1996) Growth and longevity in acanthurid fishes; an analysis of otolith increments. Mar Ecol Prog Ser 134:15-26 
Choat JH, Robertson DR (2002) Age-based studies on coral reef fishes. In: Sale PF (ed) Coral reef fishes: dynamics and diversity in a complex ecosystem. Academic Press, New York, p 57-80

Choat JH, Robertson DR, Akerman JL, Posada JM (2003) An age-based demographic analysis of the Caribbean stoplight parrotfish Sparisoma viride. Mar Ecol Prog Ser 246: 265-277

Clifton KE (1995) Asynchronous food availability on neighboring Caribbean coral reefs determines seasonal patterns of growth and reproduction for the herbivorous parrotfish Scarus iserti. Mar Ecol Prog Ser 116:39-46

Colin P, Clavijo IE (1988) Spawning activity of fishes producing pelagic eggs on a shelf edge coral reef, SW Puerto Rico. Bull Mar Sci 43:249-279

Conover DO (1990) The relation between capacity for growth and length of growing season: evidence for and implications of countergradient variation. Trans Am Fish Soc 119:416-430

Conover DO (1992) Seasonality and the scheduling of life history at different latitudes. J Fish Biol 41(Suppl B):161-178

Conover DO, Schultz ET (1995) Genotypic similarity and the evolutionary significance of countergradient variation. Trends Ecol Evol 10:248-252

Cowen RK (1990) Sex change and life history patterns of the labrid, Semicossyphus plucher, across an environmental gradient. Copeia 1990:787-795

Craig PC (1999) The von Bertalanffy growth curve: when a good fit is not enough. Naga 22:28-30

Craig MT, Pondella DJ II, Hafner JC (1999) Analysis of age and growth in 2 eastern Pacific groupers (Serranidae: Epinephelinae). Bull Mar Sci 65:807-814

Edwards AJ (1990) The fish and fisheries of Saint Helena Island. University of Newcastle on Tyne, Newcastle

Ferreira BP, Russ GR (1994) Population structure of the coral grouper, Plectropomus leopardus, on fished and unfished reefs off Townsville, Central Great Barrier Reef, Australia. Fish Bull (Wash DC) 93:629-642

Ferreira CEL, Goncalves JEA, Coutinho R (2001) Community structure of fishes and habitat complexity on a tropical rocky shore. Environ Biol Fish 61:353-369

Ferreira CEL, Floeter SR, Gasparini JL, Ferreira BP, Joyeux JC (2004) Trophic structure patterns of Brazilian reef fishes: a latitudinal comparison. J Biogeogr 31:1093-1106

Fowler AJ, Doherty PJ (1992) Validation of annual growth increments in the otoliths of 2 species of damsel fish from the southern Great Barrier Reef. Aust J Mar Freshw Res 43:1057-1068

Garvey JE, Wright RA, Stein RA (1998) Overwinter growth and survival of largemouth bass: interactions among size, food, origin and winter duration. Trans Am Fish Soc 129: $1-12$

Gilligan MR (1991) Bergmann ecogeographic trends among triplefin blennius (Teleostei: Tripterygiidae) in the Gulf of California, Mexico. Environ Biol Fish 31:3-01-305

Gust N, Choat JH, Ackermann JL (2002) Demographic plasticity in tropical reef fishes. Mar Biol 140:1039-1051

Kimura DK (1980) Likelihood methods for the von Bertalanffy growth curve. Fish Bull (Wash DC) 77:765-774

Kokita T (2004) Latitudinal compensation in female reproductive rate of a geographically widespread reef fish. Environ Biol Fish 71:213-224

Kritzer JP (2002) Variation in the population biology of stripey bass Lutjanus carponotatus within and between 2 island groups on the Great Barrier Reef. Mar Ecol Prog Ser 243: 191-207

Lewis SM, Wainwright PC (1985) Herbivore abundance and grazing intensity on a Caribbean coral reef. J Exp Mar Biol Ecol 87:215-228

Luckhurst BE, Dean JM, Reichert M (2000) Age, growth and reproduction of the lane snapper Lujanus synagris (Pisces: Lutjanidae) at Bermuda. Mar Ecol Prog Ser 203:255-261

Macintyre IG, Aronson RB (1996) Field guidebook to the reefs of Belize. Proc 8th Int Coral Reef Symp. Smithonian Tropical Research Insitute, Balboa

Manickchand-Heilman SC, Phillip DAT (2000) Age and growth of the yellowedge grouper, Epinephelus flavolimbatus, and the yellowmouth grouper, Mycteroperca interstitialis, off Trinidad and Tobago. Fish Bull (Wash DC) 98:290-298

Manly BFJ (1997) Randomization, bootstrap and Monte Carlo methods in biology, 2nd edn. Chapman \& Hall, London

Meekan MG, Ackerman JL, Wellington GM (2001) Demography and age structure of coral reef damselfishes in the tropical eastern Pacific Ocean. Mar Ecol Prog Ser 212: 223-232

Munro JL (2000) Outmigration and movement of tagged coral reef fish in a marine fishery reserve in Jamaica. Proc Gulf Caribb Fish Inst 51:557-568

Newman SJ, Williams DMcB, Russ GR (1995) Variability in the population structure of Lutjanus adetii (Castelnau, 1873) and L. quinquelineatus (Bloch, 1790) among reefs in the central Great Barrier Reef, Australia. Fish Bull (Wash DC) 94:313-329

Porch CE, Wilson CA, Nieland DL (2002) A new growth model for red drum (Sciaenops ocellatus) that accommodates seasonal and ontogenetic changes in growth rates. Fish Bull (Wash DC) 100:149-152

Present TMC, Conover DO (1992) Physiological basis of latitudinal growth differences in Menidia menidia: variation in consumption or efficiency? Funct Ecol 6:23-31

Randall JE (2002) Acanthuridae. In: Carpenter KE (ed) The living marine resources of the western Central Atlantic. 3:1801-1805. FAO, Rome

Reeson PH (1983) The biology, ecology and bionomics of the surgeonfishes, Acanthuridae. ICLARM Stud Rev 7: $178-190$

Robertson DR (1985) Sexual-size dimorphism in surgeonfishes. Proc 5th Int Congr Coral Reefs 5:403-408

Robertson DR (1988) What determines abundances of adult surgeonfishes on patch reefs in Caribbean Panamá: settlement or post-settlement events? Mar Biol 97:495-501

Robertson DR (1991) The role of adult biology in the timing of spawning of tropical reef fishes. In: Sale PF (ed) The ecology of coral reef fishes. Academic Press, New York, p 356-382

Robertson DR (1992) Patterns of lunar settlement and earlyrecruitment in Caribbean reef fishes at Panama. Mar Biol 114:527-537

Robertson DR (2001) Population maintenance among tropical reef-fishes: inferences from the biology of small-island endemics. Proc Natl Acad Sci USA 98:5668-5670

Robertson DR, Kaufmann K (1998) Assessing early-recruitment dynamics and its demographic consequences among tropical reef fishes: accommodating variation in recruitment seasonality and longevity. Aust J Ecol 23:226-233

Robertson DR, Choat JH, Posada JM, Pitt J, Ackerman JL (2005) Ocean surgeonfish Acanthurus bahianus. II. Fishing effects on longevity, size and abundance? Mar Ecol Prog Ser 295:245-256

Rocha LA, Bass AL, Robertson DR, Bowen BW (2002) Adult habitat preferences, larval dispersal and the comparative phylogeography of 3 Atlantic surgeonfishes (Teleostei: Acanthuridae). Mol Evol 11:243-252 
Roff DA (1992) The evolution of life histories: theory and analysis. Chapman \& Hall, New York

Sadovy YM, Figuerola M, Roman A (1992) Age and growth of the red hind, Epinephelus guttatus at Puerto Rico and St Thomas. Fish Bull (Wash DC) 90:516-528

Schultz ET, Conover DO (1997) Latitudinal differences in somatic energy storage: adaptive responses to seasonality in an estuarine fish (Atherinidae: Menidia menidia). Oecologia 109:516-529

Schultz ET, Conover DO (1999) Allometry of energy reserve depletion: test of a mechanism for size-dependent winter mortality. Oecologia 119:474-483

Schultz ET, Conover DO, Ehtisham A (1997) The dead of winter: size-dependent variation and genetic differences

Editorial responsibility: Charles Birkeland (Contributing

Editor), Honolulu, Hawaii, USA in seasonal mortality in Atlantic silverside (Atherinidae: Menidia menidia) from different latitudes. Can J Fish Aquat Sci 55:1149-1157

Stearns SC (1992) The evolution of life histories. Oxford University Press, Oxford

Warner RR, Chesson PL (1985) Coexistence mediated by recruitment fluctuations: a field guide to the storage effect. Am Nat 125:769-787

Williams AJ, Davies CR, Mapstone BD, Russ GA (2003) Scales of spatial variation in demography of a large coral-reef fish - an exception to the typical model? Fish Bull (Wash DC) 101:673-683

Zar JH (1999) Biostatistical analysis. 4th edn. Prentice-Hall, Upper Saddle River, NJ

Submitted: October 28, 2004; Accepted: January 24, 2005

Proofs received from author(s): June 13, 2005 